\title{
PERENCANAAN PENAHAN TANAH 15 M DENGAN DINDING KANTILEVER DI PERIMETER SWICHYARD SKYLAND JAYAPURA
}

\author{
oleh : \\ Moch. Aswanto \\ Teknik Sipil Universitas Muhammadiyah Jakarta \\ Email : aswanto@reyleigh.com
}

\begin{abstract}
Abstrak : Makalah ini menyajikan perencanaan Dinding Penahan Tanah (DPT) Kantilever Beton Bertulang, dengan aplikasi Geo5. Penggunaan perangkat lunak analitik geoteknik, diharapkan meningkatkan efisiensi man-hour insinyur dalam tahap perencanaan maupun revisi desain saat pelaksanaan fisik. Topiknya adalah desain DPT untuk ketinggian urugan tanah lebih dari $16 \mathrm{~m}$, sepanjang lebih dari 100m, yang mana kriteria struktur DPT harus relatif ringan (terkait daya dukung tanah) dan memanfaatkan bobot massa tanah yang menumpu di kaki (base) DPT untuk mengimbangi gaya lateral yang timbul. Proporsional bentuk DPT mengikuti guidance dari RSNI Geoteknik. Tinggi dinding (stem) $\mathrm{h}=10 \mathrm{~m}$, tebal $\mathrm{w}=1.1 \mathrm{~m} \sim 0.7 \mathrm{~m}$. Kaki (Base slab) tebal $=1 \mathrm{~m}$ dan lebar $=7.7 \mathrm{~m}$. Panjang keseluruhan DPT L=100m. Penyelidikan tanah, disamping parameter tanah seperti $\mathrm{cu}$, unit weight, $\phi$ dan klasifikasi tanah, informasi penting adalah kontur kedalaman lapisan utama yaitu lapisan tanah lempung dan irisannya dengan lapisan tanah berbatu. Hal ini untuk merencanakan tambahan pemancangan untuk menyalurkan beban gravitasi maupun lateral. Struktur DPT, dikontrol dengan Angka Keamanan terhadap overturning, slip, bearing-capacity, kecukupan penulangan. Kemudian analisa dan kontrol Angka Keamanan slope stability global terhadap beban gravitasi maupun kegempaan. Untuk mengalirkan air limpasan yang meresap dibelakang dinding, DPT dilengkapi dengan urugan pasir dibelakang dinding sebagai bagian sistim drainase. Dibawah urugan pasir dipasang pipa yang mengalirkan air rembesan keluar area DPT, sehingga dapat dihindari kejenuhan tanah dibelakang dinding penahan tanah.
\end{abstract}

Kata kunci : dinding penahan tanah kantilever, angka keamanan, kegempaan

\begin{abstract}
Detail design Cantilever Retaining Wall Reinforced Concrete (DPT), with consideration of the criteria for soil height of more than $15 \mathrm{~m}$ and $100 \mathrm{~m}$ length, so that a relatively light structure (related to the carrying capacity of the soil) is needed and can utilize the weight of the ground mass that rests on the base to compensate for the lateral force of the soil. The proportional form of DPT follows guidance from RSNI Geoteknik. In addition to soil parameters such as cu, unit weight, fand soil classification, important information is the depth contour of the clay soil layer and rocky soil layer, considering that DPT requires piles to resist both gravity and lateral loads. Detailed engineering of DPT utilizes Geo-5 software. The software helps accelerate the analize of the best selection of dimensional DPT, by controlling the Safety Factor (SF) against over turning, slip, bearing-capacity, and adequacy of reinforcement. Then analysis and control of global slope stability against of gravity and seismicity.
\end{abstract}

Keywords : Cantilever Retaining Wall Reinforced Concrete, Safety Factor, Slope stability

\section{Pendahuluan}

Dalam pembangunan Swichyard diarea perbukitan, seringkali terkendala dengan kontur lahan yang tidak rata. Untuk menempatkan berbagai peralatan seperti berbagai transformator, Neutral Grounding Resistance, circuit braker, 
disconnecting switch, lightning arrester, current transformer, dll perlu desain kontur lahan yang dengan sesuaian kebutuhan spesifikasi teknikalnya.

Untuk itu pekerjaan sipil cut \& fill menjadi penting untuk mempersiapkan lahan agar berkesesuaian dengan peralatan tersebut. Untuk memperkuat perbedaan kontur, konstruksi penahan tanah retaining-wall (DPT) menjadi penting.

Dalam hal ini struktur DPT dibangun dengan spesifikasi sebagai sub-sistim pembangkitan energi dan fasilitas publik dengan kategori resiko IV.

Paper ini menyajikan ringkasan runutan perencanaan dan pelaksanaan DPT, dengan struktur kantilever beton bertulang.

\section{Project Discription}

DPT didesain untuk menahan tinggi tanah 16m dibelakangnya, dengan struktur dinding DPTnya sendiri setinggi $10 \mathrm{~m}$. Struktur duduk diatas kelompok tiangpancang beton, dimana tiang-pancang berfungsi sebagai penahan friksi lateral dan beban gravitasi dikaki DPT.

Pemanfaatan tekanan tanah aktif didapat dari urugan didepan DPT setinggi $2 \mathrm{~m}$ diukur dari sisi-bawah pondasi.

Tanah disisi dibelakang DPT secara umum adalah lempung kepasiran dengan $\mathrm{c}_{u}=18$ kpa, $\gamma=16.5 \mathrm{kN} / \mathrm{m} 3$, SPT sekitar 12-20.

Tanah tepat dibawah pondasi secara umum masih lempung kepasiran setebal 1-3m, dan gradasi 1-2m kebawah ditemui lapisan pasir kasar dan fragmen batuan, SPT $>40$.

Beton yang digunakan K225 dan pembesian BJTD 40. Tiang pancang 20x20 panjang tertanam antara $2-6 \mathrm{~m}$.

\section{Problem \& Risk}

Konstruksi DPT dibangun cukup panjang, lebih dari $100 \mathrm{~m}$. Sehingga ditemui strata tanah dibawah DPT relatif bervariasi terutama ketebalan tanah lempung kepasiran dimana dilapisan ini tiang pancang ditanam agar menyumbangkan tahanan lateral. Variasi dari ketebalan lempung antara 5m-1,5m. Layer dibawah lempung langsung bertemu dengan fragmen bebatuan yang sulit dapat ditembus tiang-pancang.

Dalam pelaksanaan dilapangan, diantisipasi dengan test-pile random disepanjang $100 \mathrm{~m}$ rencana trase DPT, untuk mendapatkan data kontur lapisan fragmen-batu.

Langkah korektifnya adalah menaikan elevasi dasar pondasi DPT, elevasi dinaikan $+1 \mathrm{~m}$ agar dapat dipastikan panjang tiang-pancang dapat maksimal terpancang.

Resiko bila kelompok tiang-pancang tidak tertanam mencukupi, maka tidak optimal mengembangkan tahanan lateralnya, dan DPT dapat bergeser.

\section{Design Approach}

Kriteria perencanaan DPT seperti pada umumnya adalah kecukupan terhadap, Pembebanan normal :

Guling dengan SF $>1.5$

Slip dengan $\mathrm{SF}>1.5$

Slope Stability dengan SF $>1.5$

Pembebanan gempa :

Guling dengan $\mathrm{SF}>1$

Slip dengan $\mathrm{SF}>1$

Slope Stability dengan SF $>1$

Perencanaan struktur beton dan detailing pembesian mengacu pada SNI 2847-2013 dan kegempaan SNI 1726-2012.

Analisa kegempaan dengan metode Mononobe-Akabe. 
Perhitungan tekanan tanah pasif dengan metode Coulomb dan tekanan aktif dengan Caquot-Kerisel. Tekanan aktif yang dihitung 1/3 dari kapasitas aktifnya.

Kapasitas lateral tiang diestimasi dengan p-y properti tanah lapisan lempung model stiff-clay above watertable (Reese \& Welch 1975) setebal 3m. Lapis dibawah lempung dimodelkan sebagai sand (Reese ae all 1974). Analisa slope stability global dengan metode Bishop.

\section{Metodologi}

Menentukan propertis mekanik tanah layer per layer yang berpengaruh terhadap analisa kestabilan DPT. Data tanah yang tersedia dari CPT, SPT dan tes laboratorium. Karena titik-titik test relatif jauh dari lokasi DPT, maka verifikasinya adalah dengan mempelajari kondisi tanah sesungguhnya diarea yang sudah di-cut dan terbangun, sehingga bisa didapatkan gambaran potongan layering dari keseragaman profil tanah.

Analisa dengan kriteria diatas diinput ke perangkat lunak Geo5 Retaining Wall untuk mendapatkan gaya-gaya yang bekerja pada DPT.

Verifikasi terhadap slope-stability dengan perangkat lunak Geo5 Slope Stability.

Estimasi daya dukung tanah dibawah DPT dihitung manual dengan metode Terzaghi dengan modifikasi bearing capacity factor oleh Brinch Hansen dan Mayerhof dan modifikasi faktor bentuk sesuai Terzaghi \& Peck.

Estimasi kapasitas lateral tiang dihitung menggunakan perangkat lunak Lpile.

Estimasi kapasitas daya dukung vertikal dihitung manual dari data CPT dan SPT (Manual Pondasi Tiang, Universitas Parahiyangan).

Besaran beban horizontal yang timbul ditahan oleh friksi tanah dan pondasi, tahanan aktif dan tiang-pancang, kesesuaiannya dihitung manual dari hasil analisa Geo5 dan hasil analisa Lpile. Beban yang tidak dapat ditahan oleh sistim DPT, dilimpahkan ke tiang-pancang.

Besaran beban vertikal, seluruhnya ditahan oleh lapisan tanah dibawah pondasi dengan tegangan ijin $200 \mathrm{kpa}$.

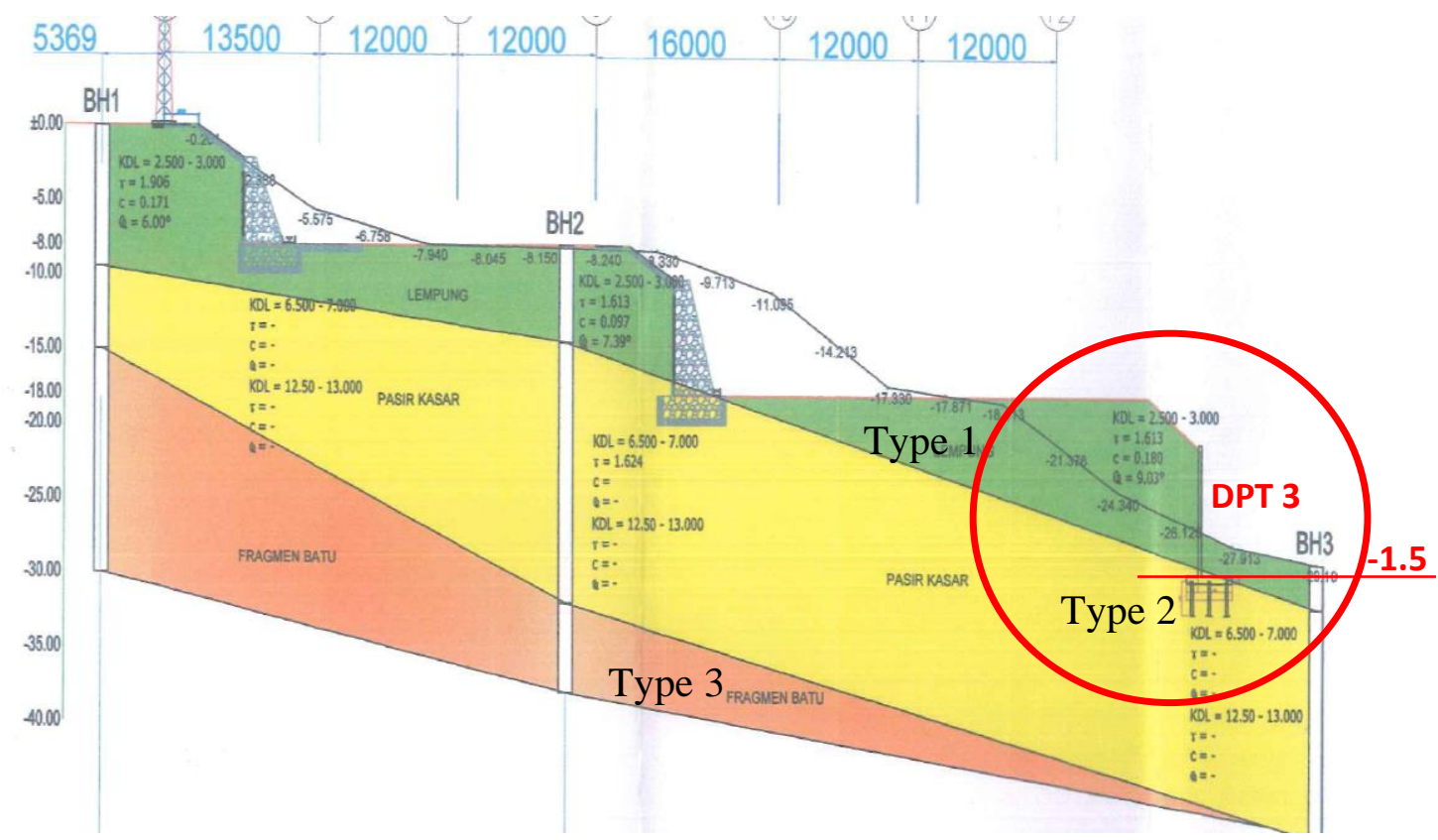

Gambar 1. Lapisan Tanah DPT 3 


\section{Geotechnical Model}

Tiga layer dominan dibawah lokasi swichyard dapat digambarkan dalam gambar 1. Input model layer-layer tanah pada perangkat lunak tersaji dalam gambar 2 .

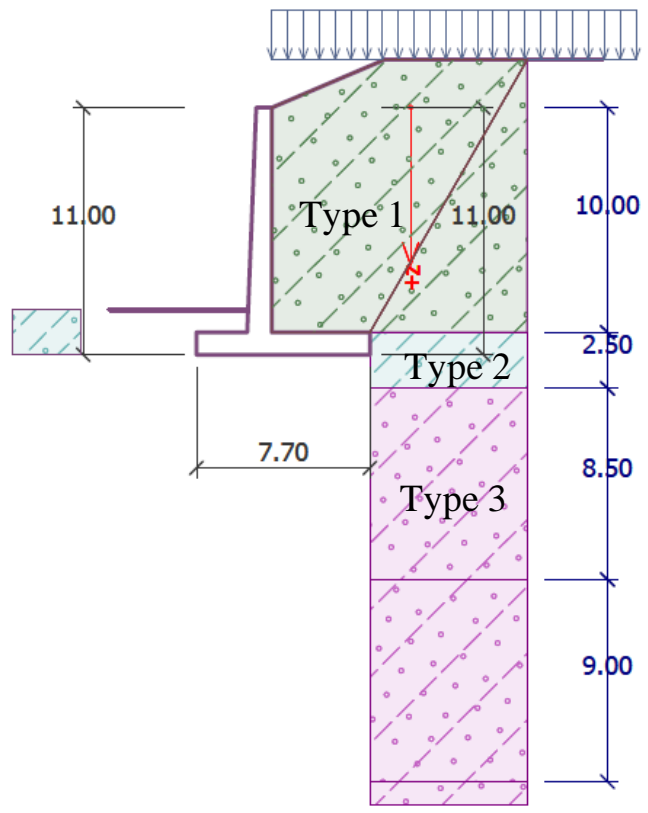

Gambar 2. Model Dan Ketebalan Layer

Tanah
List dari masing-masing properties tiap layer disajikan di tabel 1 . Untuk nilai dengan tanda * adalah nilai yang ditentukan berdasarkan literatur dan pendekatan evaluasi lapangan dari pekerjaan lapisan tanah yang sudah di-cut.

Tabel 1. Properti Tanah

\begin{tabular}{|c|c|c|c|c|c|c|c|c|c|c|}
\hline \multirow{2}{*}{ No } & \multirow{2}{*}{ Parameter } & \multicolumn{3}{|c|}{ Type 1} & \multicolumn{3}{|c|}{ Type 2} & \multicolumn{3}{|c|}{ Type 3} \\
\hline & & Nama & Nilai & Satuan & Nama & Nilai & Satuan & Nama & Nilai & Satuan \\
\hline 1 & $C P T /$ Sondir & $q \mathrm{qc}$ & & $\mathrm{kg} / \mathrm{cm} 2$ & qc & & $\mathrm{kg} / \mathrm{cm} 2$ & $q c$ & - & $\mathrm{kg} / \mathrm{cm} 2$ \\
\hline 2 & $S P T$ & $\mathrm{~N}$ & 20 & & $\mathrm{~N}$ & 46 & & $\mathrm{~N}$ & 48 & \\
\hline 3 & Poison Ratio & $v$ & $0.25^{*}$ & & $v$ & $0.25 *$ & & $v$ & & \\
\hline \multirow[t]{2}{*}{4} & Compressibility Index & $\mathrm{CC}$ & 0,187 & & $\mathrm{CC}$ & & & $\mathrm{CC}$ & & \\
\hline & & $\mathrm{CV}$ & 3.6E-02 & & $\mathrm{CV}$ & & & $\mathrm{CV}$ & & \\
\hline 5 & Unit Weight & $\gamma t$ & 16,5 & $\mathrm{kN} / \mathrm{m} 3$ & $\gamma t$ & 18,0 & $\mathrm{kN} / \mathrm{m} 3$ & $\gamma \mathrm{t}$ & 20,0 & $\mathrm{kN} / \mathrm{m} 3$ \\
\hline 6 & Cohesion undrained & $\mathrm{cu}(\mathrm{UU})$ & 18,00 & kpa & c & $16^{*}$ & kpa & c & & kpa \\
\hline 7 & Sudut Geser Dalam & (UU) & 9 & o & $\phi$ & $40 *$ & o & $\phi$ & $35 *$ & 0 \\
\hline \multirow[t]{3}{*}{8} & Plastic Limit & $\mathrm{PL}$ & 18,86 & $\%$ & $\mathrm{PI}$ & & $\%$ & $\mathrm{PI}$ & & $\%$ \\
\hline & Liquid Limit & $\mathrm{LL}$ & 30,22 & $\%$ & LL & & $\%$ & $\mathrm{LL}$ & & $\%$ \\
\hline & Plasticity Index & $\mathrm{PI}$ & 11,36 & $\%$ & $\mathrm{PI}$ & & $\%$ & $\mathrm{PI}$ & & $\%$ \\
\hline \multirow[t]{5}{*}{9} & Grain Size & & & & & & & & & \\
\hline & Kerikil & & 0 & $\%$ & & 0 & $\%$ & & 23,33 & $\%$ \\
\hline & Pasir & & 38,91 & $\%$ & & 45,05 & $\%$ & & 48,04 & $\%$ \\
\hline & Silt & & 54,82 & $\%$ & & 54,11 & $\%$ & & 28,63 & $\%$ \\
\hline & Lempung & & 6,27 & $\%$ & & 0,83 & $\%$ & & 0 & $\%$ \\
\hline 10 & Adhesion structure-soil & & $24 *$ & kpa & & $19 *$ & kpa & & & kpa \\
\hline 11 & Soil pressure at rest & \multicolumn{3}{|c|}{ cohesive } & \multicolumn{3}{|c|}{ cohesive } & \multicolumn{3}{|c|}{ cohesionless } \\
\hline 12 & Stress-state & \multicolumn{3}{|c|}{ total } & \multicolumn{3}{|c|}{ effective } & \multicolumn{3}{|c|}{ effective } \\
\hline 13 & Angle of friction structure-soil & \multicolumn{3}{|r|}{0} & \multicolumn{3}{|r|}{ o } & \multicolumn{3}{|c|}{19} \\
\hline 14 & Diskripsi & \multicolumn{3}{|c|}{$\begin{array}{l}\text { SM, Silt Lempung pasiran, } \\
\text { coklat abu-abu, agak padat, } \\
\text { agak lekat, agak liat. }\end{array}$} & \multicolumn{3}{|c|}{$\begin{array}{l}\text { MS, Sandy Silt, padat sampai } \\
\text { sangat padat }\end{array}$} & \multicolumn{3}{|c|}{$\begin{array}{l}\text { SP, Pasir kasar abu-abu, } \\
\text { lepas sampai padat, ada } \\
\text { fragmen batuan. }\end{array}$} \\
\hline
\end{tabular}


Nilai poison ratio didekati dengan tabel Bowles (1968) untuk tanah lempung berpasir 0.2-0.3. Lekatan antara permukaan struktur beton dan tanah diambil dari nilai kategori medium-stiff cohesive soil dalam range 12-24-36 kpa. Angle of friction structure-soil antara tanah dan permukaan struktur beton didekati dengan tabel NAVFAC, antara massconcrete vs silty clay diambil $19^{0}$.

\section{Dimensioning DPT Beton}

Sebagai guidance mengikuti RSNI Geoteknik, dimensi DPT menjadi seperti dalam Gambar 3. Kemudian dilanjutkan dengan mengaplikasikan beban dan menverifikasi SF, apakah sudah sesuai dengan kriteria yang sudah ditetapkan.

\section{Pembebanan}

Beban yang bekerja diluar beban pasif tanah adalah beban tanah timbunan diatas DPT yaitu sebesar $10 \mathrm{kN} / \mathrm{m}$ yang sifatnya permanen.

Beban gempa didekati dengan kondisikondisi sebagai berikut :

$$
\begin{aligned}
& \text { Tanah Sedang/SD } \\
& \mathrm{Ss}=1.5 \mathrm{~g}, \mathrm{~S} 1=0.6 \mathrm{~g}
\end{aligned}
$$

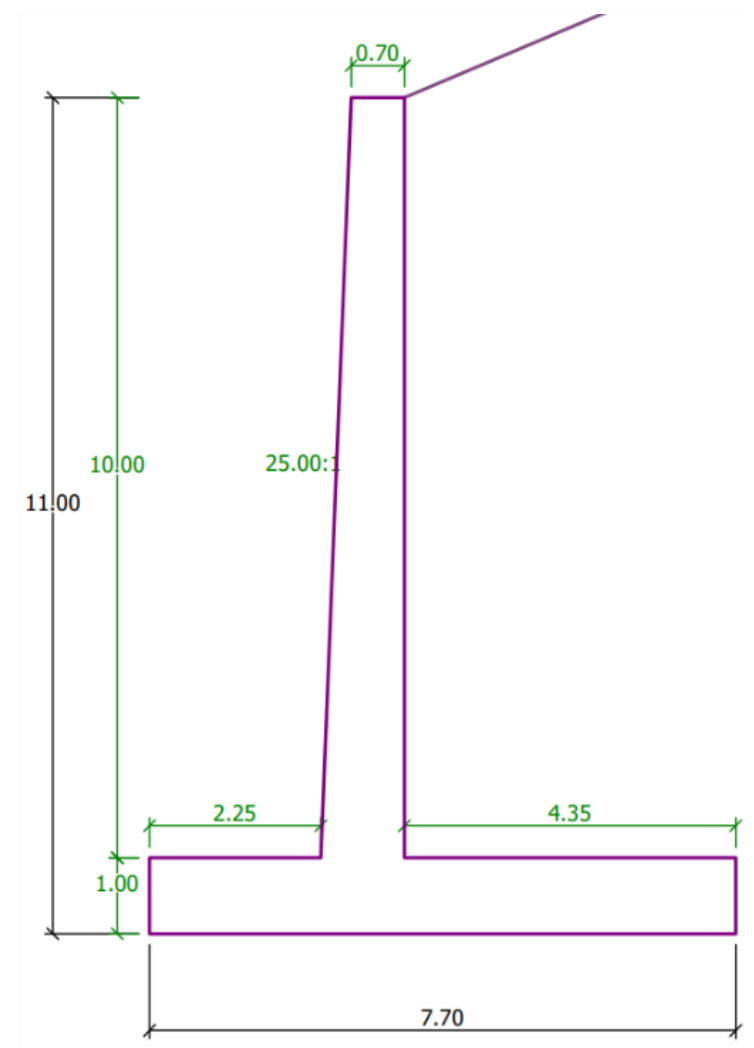

Gambar 3. Dimensional DPT

Keutamaan $=1.5$

PGA sesuai situs $=0.7 \mathrm{~g}$

Metode analisa Mononobe-Akabe

K-horizontal $=0.107$

K-vertikal tidak ditinjau.

Tinggi kerja beban $\mathrm{kH}=0.66$

\section{Analisis}

Desain DPT dengan volume beton yang relatif banyak, mencapai $1800 \mathrm{~m} 3$, dan tulangan 210 ton, maka efisiensi dari desain menjadi ini prioritas.

Desainer harus dapat menghubungkan antara elemen struktur, pembebanan dan iteraksi keduanya dengan tanah sedetail mungkin, untuk mendapatkan SF yang optimum.

Dengan kompleksitas tersebut diatas, penggunaan perangkat lunak yang khusus diprogramasi untuk desain Dinding Penahan Tanah dan analisa Slope-stabilitynya menjadi keniskayaan.

Hasil analisa sebagai berikut : 


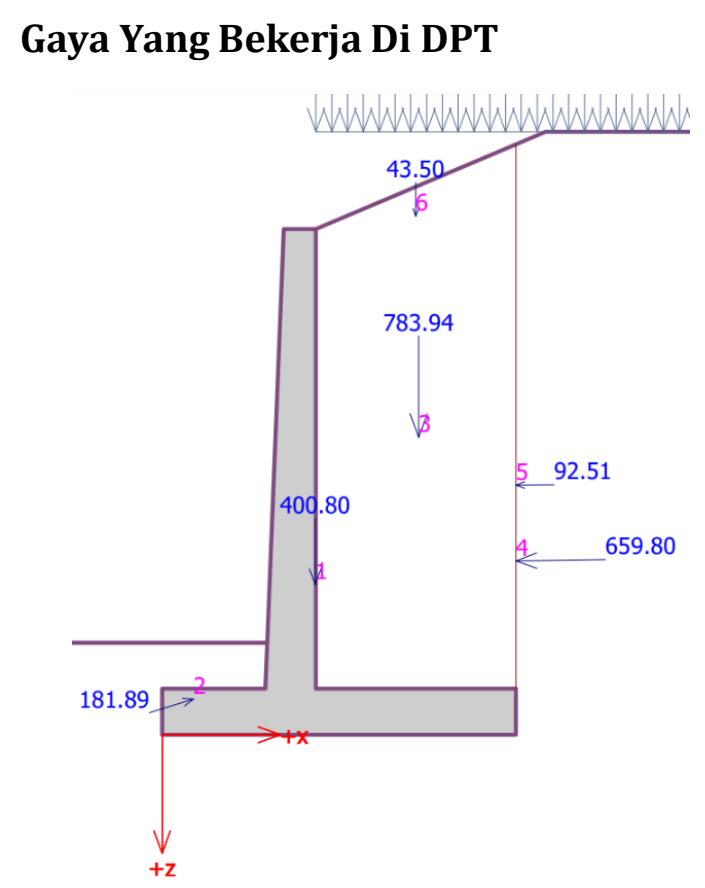

Gambar 4. Gaya beban permanen (kN)

Dari gambar 5 dapat diketahui konfigurasi, besaran dan arah dari gaya-gaya yang bekerja pada struktur DPT.

Sehingga verifikasi overturning-stability sebagai berikut :

Momen resisting $=5994 \mathrm{kNm} / \mathrm{m}$

Momen overturning $=2860 \mathrm{kN} / \mathrm{m}$

$\mathrm{SF}=2.1>1.5 \mathrm{ok}$

Verifikasi Slip

Tahanan horizontal $=1077 \mathrm{kN} / \mathrm{m}$

Gaya aktif horizontal $=578 \mathrm{kN} / \mathrm{m}$

$\mathrm{SF}=1.86>1.5$

Verifikasi Slope-stability Bishop

$\Sigma$ active forces $\mathrm{Fa}=2113 \mathrm{kN} / \mathrm{m}$

$\Sigma$ passive forces $\mathrm{Fp}=3177 \mathrm{kN} / \mathrm{m}$

Sliding Moment $\mathrm{Ma}=56602$ $\mathrm{kNm} / \mathrm{m}$

Resisting moment $\mathrm{Mp}=85095$ $\mathrm{kNm} / \mathrm{m}$

$\mathrm{SF}=1.5>=1.5$

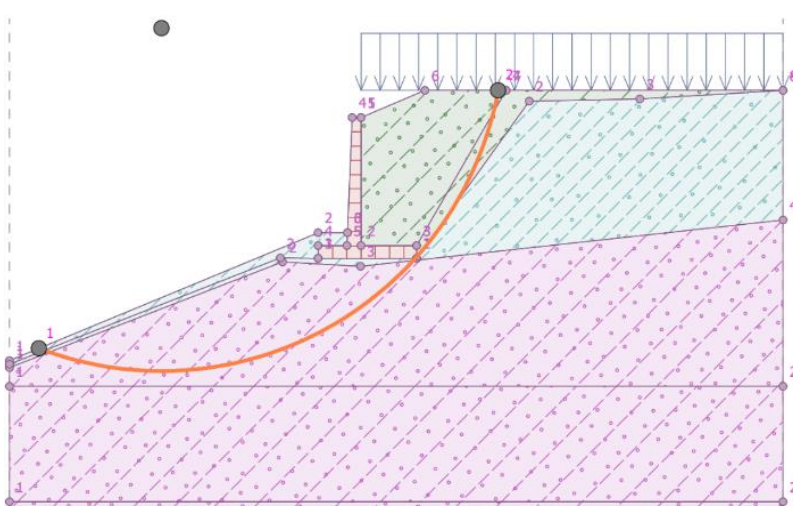

Gambar 5. Verifikasi slope stability $\mathrm{SF}=1.5$

Gaya-gaya akibat modelisasi gempa (psedo) sebagai berikut :

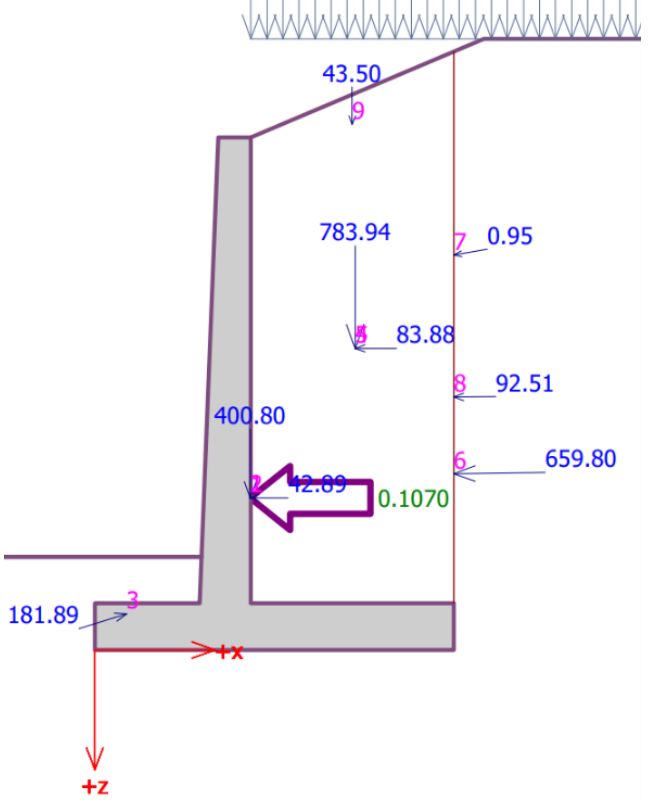

Gambar 6. Beban Gempa (kN)

Verifikasi overturning stability sebagai berikut :

Momen resisting $=5995 \mathrm{kNm} / \mathrm{m}$

Momen overturning $=3552 \mathrm{kN} / \mathrm{m}$ $\mathrm{SF}=1.69>1.0 \mathrm{ok}$

Verifikasi Slip

Tahanan horizontal $=1059 \mathrm{kN} / \mathrm{m}$

Gaya aktif horizontal $=706 \mathrm{kN} / \mathrm{m}$

$\mathrm{SF}=1.50>1.0 \mathrm{ok}$

Verifikasi Slope-stability Bishop

$\Sigma$ active forces $\mathrm{Fa}=2350 \mathrm{kN} / \mathrm{m}$

$\Sigma$ passive forces $\mathrm{Fp}=2988 \mathrm{kN} / \mathrm{m}$

Sliding Moment $\mathrm{Ma}=62338$ $\mathrm{kNm} / \mathrm{m}$ 
$\mathrm{kNm} / \mathrm{m}$

$$
\text { Resisting moment } \quad \mathrm{Mp}=79257
$$

$\mathrm{SF}=1.27>1.0 \mathrm{ok}$

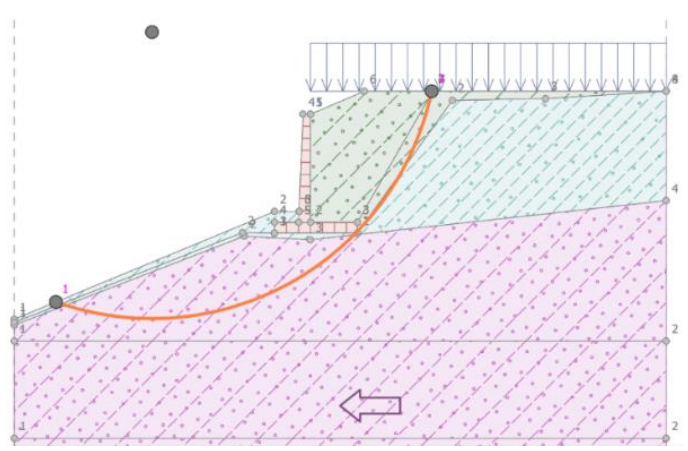

Gambar 7. Verifikasi slope stability $\mathrm{SF}=1$

\section{Penulangan DPT}

Pembesian pada Wall :

Load factor pada berat sendiri beton $=1.2$, tanah pasif $L F=1$, tanah aktif $L F=1.2$, beban tanah dan swichyard $\mathrm{LF}=1.6$. Dipasang tulangan pokok 11 D25 per 1 meter lebar dengan As $=5573 \mathrm{~mm} 2$, sedangkan kebutuhan As=4190 mm2. Selimut beton $75 \mathrm{~mm}, \quad$ K225 dan BJTD40. Geo5 memberikan cheklist sebagai berikut:

Shear satisfactory 95,9\%

Flexure satisfatory 76,5 \%

Design priciple $62 \%$

Pembesian pada Pondasi, tulangan sisi bawah :

Load factor pada berat sendiri beton $=1.2$, tanah pasif $L F=1$, tanah aktif $L F=1.2$, beban tanah dan swichyard $\mathrm{LF}=1.6$. Dipasang tulangan pokok 11 D22 per 1 meter lebar dengan As=4267 mm2, sedangkan kebutuhan As=3178 mm2. Selimut beton $75 \mathrm{~mm}, \quad$ K225 dan BJTD40. Geo5 memberikan cheklist sebagai berikut :

Shear required reinforcement

Flexure satisfatory $75.6 \%$

Design priciple $73.8 \%$

Ditambahkan secara manual kebutuhan tulangan geser berupa ties/kait vertikal dengan D13. Untuk tulangan atas, menggunakan tulangan minimum sesuai persyaratan SNI 2847.

Pembesian pada Pondasi, tulangan sisi atas dibagian depan (wall heel) :

Load factor pada berat sendiri beton $=1.2$, tanah pasif $L F=1$, tanah aktif $L F=1.2$, beban tanah dan swichyard $\mathrm{LF}=1.6$. Dipasang tulangan pokok 14 D25 per 1 meter lebar dengan As=7093 mm2, sedangkan kebutuhan As=6418 mm2. Selimut beton $75 \mathrm{~mm}, \quad$ K225 dan BJTD40. Geo5 memberikan cheklist sebagai berikut :

Shear required reinforcement

Flexure satisfatory $91.4 \%$

Design priciple $44.3 \%$

Ditambahkan secara manual kebutuhan tulangan geser berupa ties/kait vertikal dengan D13. Detail pembesian tersaji dalam gambar 8 .

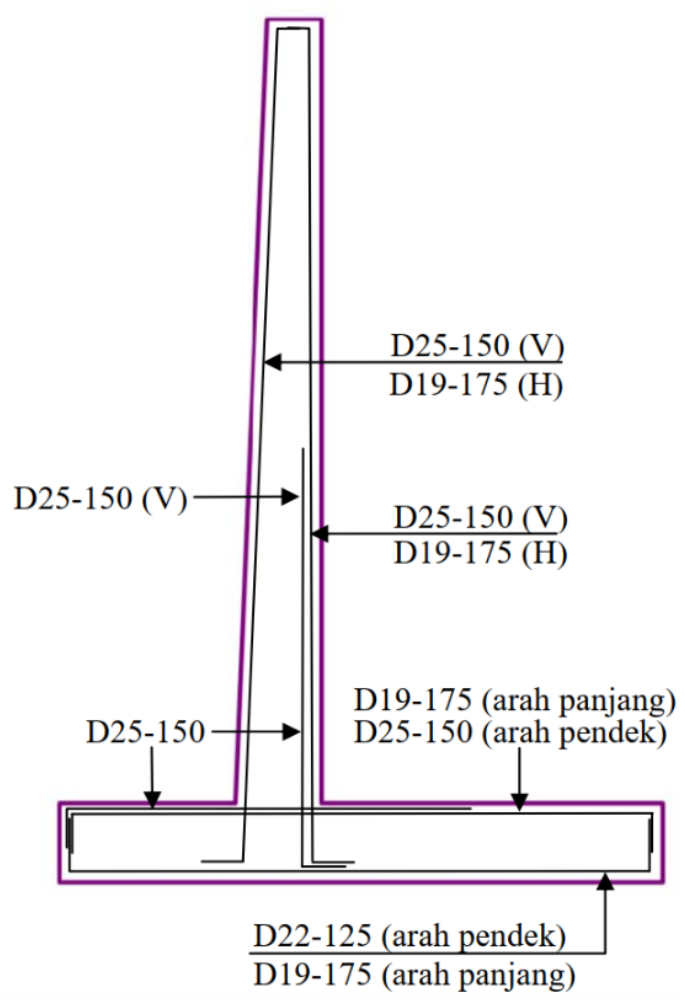

Gambar 8. Pembesian

\section{Bearing Capacity}

Tegangan yang terjadi pada sisi bawah pondasi adalah $223 \mathrm{kpa}$, sedangkan kapasitas ijin tanah $200 \mathrm{kpa}$, sehingga SF = 
$0,89<2$. Sehingga beban dipikulkan ke tiang pancang untuk disalurkan kelapisan SP (type 3). Kapasitas vertikal tiang pancang 20x20 L=6m berdasarkan CPT adalah 12-20 ton (lokasi CPT 30m dari DPT) dan berdasarkan SPT adalah 19.5 ton.

\section{Lateral Capacity}

Kapasitas lateral tiang pancang berdasarkan analisa p-y yang diprogramasi dalam perangkat lunak Lpile adalah $750 \mathrm{~kg} /$ tiang.

\section{Field Performance}

Pelaksanaan konstruksi didahului dengan penggalian tanah dibelakang dan dibawah DPT, pada saat itu kita dapat mengevaluasi parameter mekanik tanah yang kita gunakan dalam permodelan, apakah perlu diperbaiki atau tidak.

Kemudian dilanjutkan pekerjaan pemancangan, dimana saat itu kita evaluasi seberapa dalam tiang dapat menembus lapisan pasir padat berfragmen bebatuan. Karena variasi kedalaman lapisan ini bervariasi sepanjang $100 \mathrm{~m}$, maka evaluasi daya dukung tanah baik lateral maupun horizontal dikerjakan pada tahapan ini. Penyesuaian desain seperti penambahan dan pengurangan pancang dikerjakan pada tahapan ini.

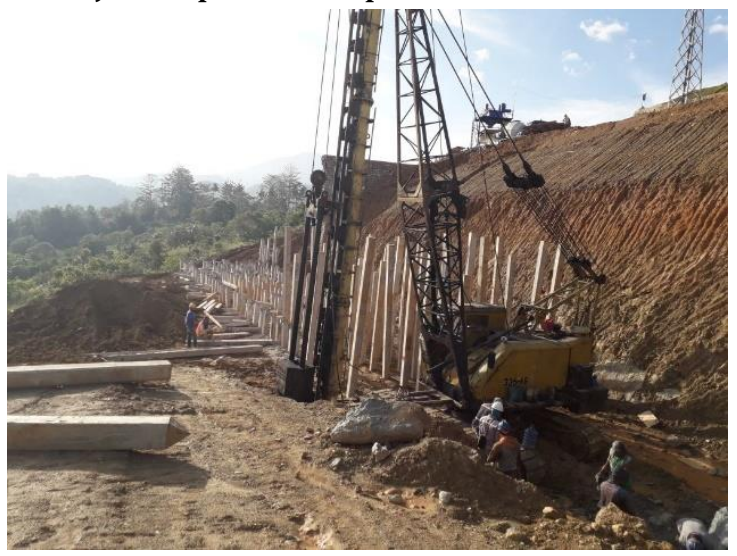

Gambar 9. Persiapan Lahan dan Pemancangan
Fabrikasi tulangan, pemasangan, dan pengecoran relatif tidak terjadi permasalahan dilapangan, karena ketidakterkaitannya dengan kondisi geoteknik. Pengurugan kembali, pengurugan pasir untuk drainase dan pekerjaan yang mengikutinya, dimulai setelah terpasang titik-titik paku koordinat untuk monitoring posisi DPT apakah bergerak, seberapa jauh pergerakan dan arahnya selama masa pemadatan tanah dan sepanjang umur DPT.

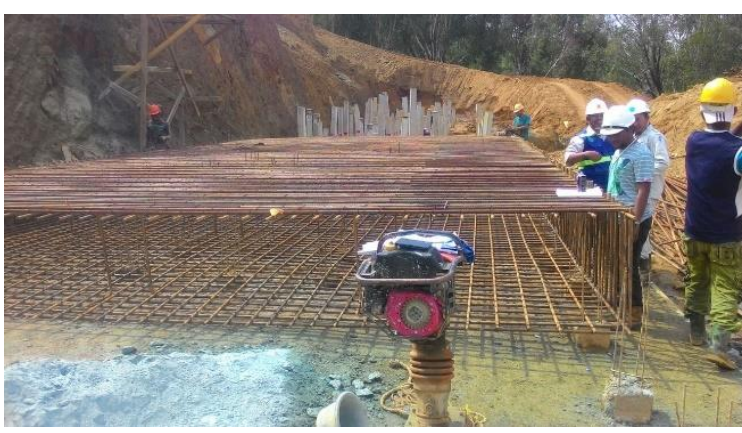

Gambar 10. Fabrikasi Pembesian

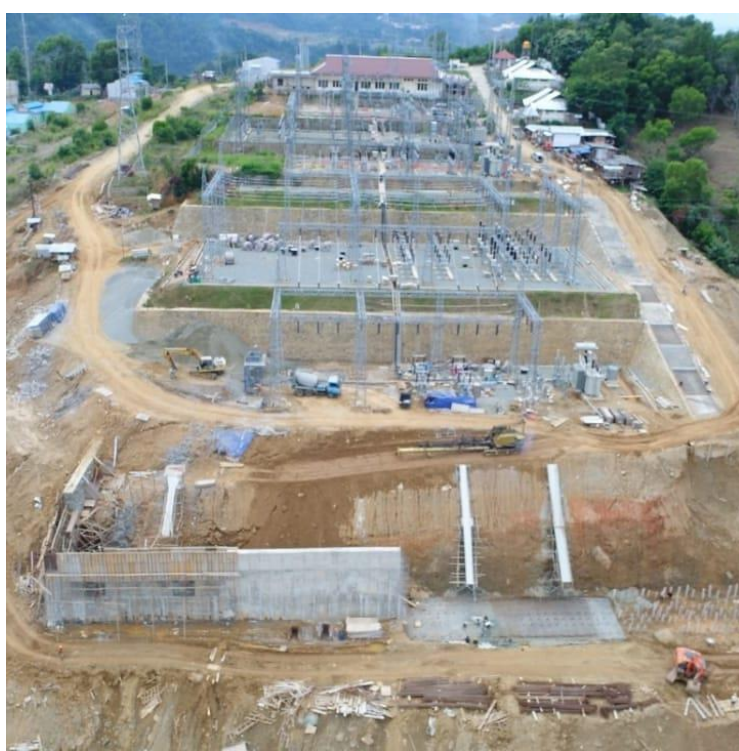

Gambar 11. Pengecoran 


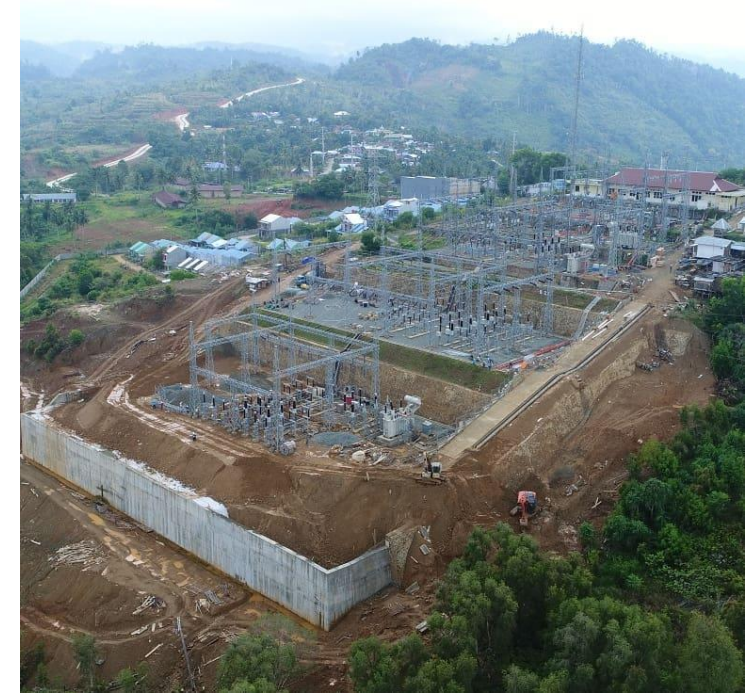

Gambar 12. Pengurugan dan Pemasangan Geotekstil

\section{Kesimpulan}

Perencanaan struktur DPT menggunakan perangkat lunak geoteknik yang khusus diperuntukan untuk desain DPT dapat membantu mempercepat waktu desain, baik dalam tahap preliminari menentukan bentuk yang paling optimal sampai menentukan pembesian tulangantulangan utama.

Pengetahuan detailing pembesian diperlukan untuk dapat menyelesaikan perencanaan DPT. Disamping pengetahuan geoteknik dan pendekatan numerik terhadap propertis mekanik tanah.

Proses desain tidak berhenti sampai selesainya dokumen perencanaan, tetapi berlanjut sampai pekerjaan fisik di lapangan selesai, mengingat penyesuaian desain diperlukan bila menemukan kondisi strata tanah yang berbeda dengan rencana, memastikan sistim drainase dapat berfungsi dan berbagai dinamika kendala dalam pekerjaan konstruksi yang perlu diselesaikan oleh perencana.

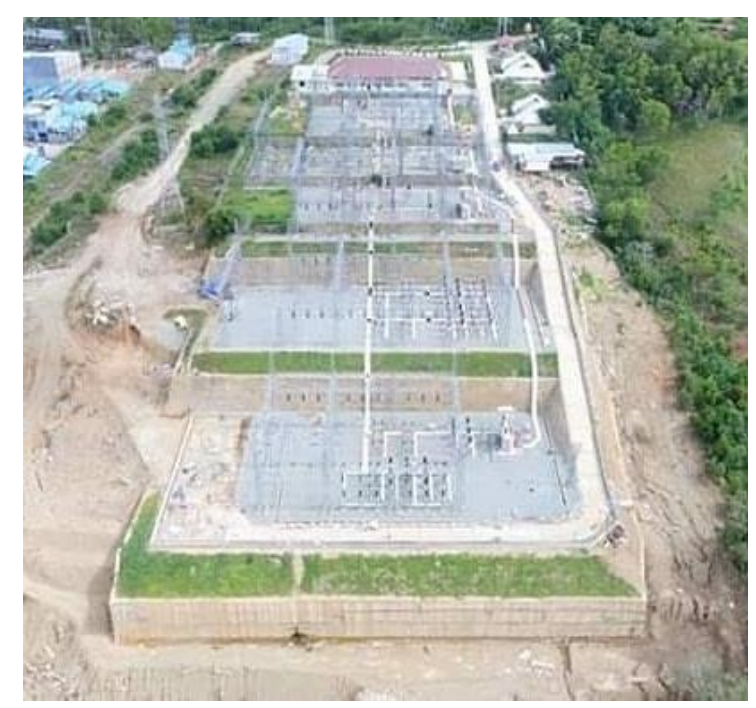

Gambar 13. Penanaman Rumput

\section{Daftar Pustaka}

Badan Standarisasi Nasional, 2016. RSNI2 Persyaratan Perancangan Geoteknik. Badan Standarisasi Nasional, 2012. SNI 1726-2012 Tata Cara Perencanaan Ketahanan Gempa.

GE05, 2018. Engineering Manual Walls \& Stability Analysis.

Gouw Tjie-Liong, 2015. Kestabilan Lereng, Tekanan Tanah Lateral dan Galian Dalam, Pelatihan Geoteknik.

M. Aswanto, 2017. Perbaikan dan Analisa Resiko Terhadap Kelongsoran Lereng, PT United Tractors Berau, PT AWK.

M. Aswanto, 2015 Analisa Stabilitas Lereng Proyek Facility PAMA di Kalteng, PT Pamapersada Nusantara, PT MGU. 
